\title{
Inadimplência e Colateral na Teoria Microeconômica do Equilíbrio dos Mercados
}

\author{
Ricardo Luis Chaves Feijó*
}

\author{
Conteúdo: 1. Introdução; 2. O Programa de Pesquisa do Equilíbrio Geral Antes do Problema \\ da Inadimplência; 3. Otimalidade do Equilíbrio Quando o Mercado é Incompleto; \\ 4. Inadimplência no Equilíbrio Geral; 5. Colateral no Equilíbrio Geral; \\ 6. Conclusão. \\ Palavras-chave: Equilibrio Geral; Inadimplência; Colateral. \\ Códigos JEL: $\mathbf{J} 5$.
}

Este ensaio apresenta a evolução dos mais recentes modelos matemáticos de equilíbrio geral, começando pelo modelo de mercadorias contingentes, passando pelo modelo sequencial com ativos financeiros, até chegar ao caso de equilíbrio com inadimplência e mercados de ativos "colateralizados". Para tanto, discorre-se sobre as principais ideias com respeito à aplicação da teoria microeconômica do equilíbrio geral a situações que envolvam a troca e a alocação de recursos sob condições de incerteza. Depois, apresentam-se as condições de equilíbrio geral quando os mercados financeiros são incompletos. Faz-se uma avaliação crítica das hipóteses assumidas por tais modelos. Na sequência, introduz-se a discussão do papel da inadimplência no equilíbrio geral desses mercados, e finalmente discute-se o efeito das garantias (colaterais) para o equilíbrio geral dos mercados. Considerando-se uma seleção de oito importantes estudos, o artigo examina os pressupostos matemáticos e comportamentais de cada família de modelos e passa em revista os principais teoremas que demonstram, ou não, a existência do equilíbrio geral em mercados incompletos de ativos com inadimplência e colaterais. Segue ainda uma classificação das hipóteses subjacentes ao conjunto de teoremas de equilíbrio geral demonstrados na literatura considerada.

This paper presents the evolution of the most recent mathematical models of general equilibrium, starting with the model of contingent commodities, through the sequential model with securities, even to the case of equilibrium with default and collateralized securities markets.

\footnotetext{
${ }^{*}$ Professor da Universidade de São Paulo (FEA-RP/USP). E-mail: riccfei j@usp. br
} 
To this end, we discuss on the main ideas regarding the application of microeconomic theory of general equilibrium to situations involving the exchange and resource allocation under conditions of uncertainty. Then we present the conditions of general equilibrium when financial markets are incomplete. We make a critical evaluation of assumptions for such models. Further, we introduce the discussion of the role of default in market general equilibrium, and finally we discuss the effect of collateral for the general equilibrium. Given a selection of eight important papers, the article examines the assumptions and mathematical behavioral models of each family and examines the main theorems that demonstrate whether or not the existence of general equilibrium in incomplete security markets with default and collateral. Still follows a classification of the assumptions underlying the set of theorems of general equilibrium shown in the literature considered.

\section{INTRODUÇÃO}

Os mercados de ativos financeiros podem ser instáveis mesmo com a presença de garantias em ativos físicos (colateral). No entanto, os mais recentes modelos matemáticos de equilíbrio geral mostram que, sob certas condições, mercados de ativos na forma de empréstimos "colateralizados" ao menos se equilibram. Então se pretende, neste ensaio, apresentar a evolução desses modelos. Para tanto, o artigo estrutura-se da seguinte forma: na primeira seção discorre-se sobre as principais ideias com respeito à aplicação da teoria microeconômica do equilíbrio geral a situações que envolvam a troca e a alocação de recursos sob condições de incerteza.

Na classe de modelos que formalizam incerteza, tem-se o chamado equilíbrio de Arrow-Debreu, isto é, um equilíbrio walrasiano no qual mercadorias contingentes são negociadas. É amplamente sabido que um equilíbrio de Arrow-Debreu resulta em uma alocação de risco ótima no sentido de Pareto. Enquanto que nesse modelo os agentes trocam mercadorias contingentes, eles podem comercializar ativos financeiros no chamado modelo de Radner. Pretende-se, nessa seção inicial, revisar ideias canônicas antes de fazer-se uma avaliação crítica da literatura de fronteira que considera a presença de inadimplência e garantias físicas no mercado de ativos.

Na segunda seção, apresentam-se as condições para o equilíbrio geral quando os mercados financeiros são incompletos. Faz-se uma avaliação crítica das hipóteses assumidas por tais modelos. Na seção subsequente, introduz-se a discussão do papel da inadimplência no equilíbrio geral desses mercados. Veremos que a inadimplência não implica desequilíbrio. Ou seja, o conceito de equilíbrio é consistente com a ocorrência dela. Finalmente outra seção discute o efeito das garantias físicas para o equilíbrio geral dos mercados. Considerando-se uma seleção de oito importantes estudos, iremos examinar os pressupostos matemáticos e comportamentais de cada família de modelos e passar em revista os principais teoremas que demonstram, ou não, a existência do equilíbrio geral em mercados incompletos de ativos com inadimplência e garantias físicas. Segue ainda uma breve seção conclusiva.

\section{O PROGRAMA DE PESQUISA DO EQUILÍBRIO GERAL ANTES DO PROBLEMA DA INADIMPLÊNCIA}

Considere a descrição tradicional de uma economia de mercado com mercadorias contingentes: tem-se um vetor mercadorias estado-contingente $x \in \mathbb{R}^{L S}$, no qual $L$ é o número de mercadorias físicas e $S$ o de estados da natureza. A dotação do consumidor $i$ é representada por um vetor de 
mercadorias contingentes $\omega_{i} \in \mathbb{R}^{L S}$. Representam-se as preferências do consumidor sobre um vetor de mercadorias contingentes por uma relação de preferências racionais $\succsim_{i}$, definidas em um conjunto de consumo $X_{i} \subset \mathbb{R}^{L S}$.

Falta especificar a participação nos direitos de propriedade de cada consumidor $i$ em relação à firma $j$. Por simplicidade, supõem-se que tais participações não são estado-contingentes, então para qualquer estado, seja $\theta_{j i} \geq 0$ a participação nos direitos de propriedade da firma $j$ pelo consumidor $i$. Por definição, $\sum_{i} \theta_{j i}=1$ a cada $j$. Encerra-se a descrição de uma economia na qual a incerteza importa com a identificação de um vetor de produção estado-contingente $y \in \mathbb{R}^{L S}$ e um conjunto de produção $Y_{i} \subset \mathbb{R}^{L S}$.

Pode-se postular que o mercado é completo e então se chega a um equilíbrio do tipo Arrow-Debreu sempre que, para todo agente $i$ e todas as firmas $j$, as três seguintes proposições estejam satisfeitas para uma alocação $\left(x^{*}, y^{*}\right) \subset \mathbb{R}^{L S(I+J)}$, na qual $I$ é o número de agentes e $J$ o número de firmas, levando-se também em consideração um sistema de preços para as mercadorias contingentes $p \in \mathbb{R}^{L S}$.

(i) $y_{j}^{*}$ satisfaz $p y_{j}^{*} \geq p y_{j}$;

(ii) $x_{i}^{*}$ é máximo para $\succsim_{i}$ no conjunto orçamentário $\left\{x_{i}^{*} \in X i: p x_{i} \leq p \omega_{i}+\sum_{j} \theta_{j i} p y_{j}^{*}\right\}$;

(iii) $\sum_{i} x_{i}^{*}=\sum_{j} y_{j}^{*}+\sum_{i} \omega_{i}$.

Todos os teoremas de bem-estar provados para um equilíbrio walrasiano também se aplicam a esse novo modelo de equilíbrio. Contudo, no contexto de Arrow-Debreu a hipótese tradicional de convexidade nas relações de preferência $\succsim_{i}$ deve agora ser interpretada como aversão ao risco pelo agente. O "primeiro teorema do bem-estar" assegura que o equilíbrio de Arrow-Debreu satisfaz o critério de otimalidade de Pareto. Portanto, a possibilidade de trocas de mercadorias contingentes resulta numa alocação de risco eficiente.

Não obstante, tal cenário não se afigura muito realista. Pois, ele imagina que todas as trocas ocorram em simultâneo e antes que a incerteza seja resolvida. Um modelo mais realista deveria considerar que as trocas ocorrem sequencialmente ao longo do tempo. Nesse sentido, a extensão mais conhecida do modelo de Arrow-Debreu fora proposta num estudo desenvolvido por Roy Radner em $1972 .{ }^{1}$ Em um equilíbrio de Radner, as trocas ocorrem ao longo do tempo. Na versão mais simples do modelo, consideram-se apenas economias de troca, isto é, não se verifica nenhuma produção. Assume-se que existam duas datas, $t=0$ e $t=1$, que nenhuma informação esteja presente em $t=0$, e que a incerteza seja completamente resolvida em $t=1$. Destarte, tem-se uma árvore de eventos muito simples. Assume-se que não exista nenhum consumo em $t=0$. Então as transações de mercado para as $L S$ possíveis mercadorias contingentes são iniciadas nesse instante. Tais mercados são para entrega de bens em $t=1$ (forward markets). Quando chega esse período, um estado da natureza s é revelado e os contratos são executados.

Nota-se que no período 1 não viceja nenhum incentivo para nova barganha, pois, não seria mais possível ganhos adicionais com nova rodada de negociação, tendo-se em conta que o equilíbrio alcançado já é um ótimo de Pareto. No entanto, seria muito interessante examinar o efeito de se relaxar alguma hipótese do modelo simples. Por exemplo, imagina-se agora que nem todos os $L S$ mercados contingentes estejam disponíveis em $t=0$. Neste caso, uma das trocas iniciais que conduz a uma alocação ótima de Pareto pode não mais ser factível e então é perfeitamente possível que em $t=1 \mathrm{o}$ consumo resultante não seja uma alocação ótima de Pareto. É evidente que, nesse contexto, haveria então um incentivo para reabrir o mercado e iniciarem-se novas trocas.

Mesmo em tais circunstâncias, portanto, sob certas condições ainda poderia ser o caso em que novas possibilidades de trocas em $t=1$ voltem a garantir que a otimalidade de Pareto seja alcançada. Conforme já bem conhecido na literatura, na condição em que ao menos uma mercadoria física possa

\footnotetext{
${ }^{1}$ Radner (1972).
} 
ser contingencialmente negociada em $t=0$, a possibilidade de futuras negociações em $t=1$ poderia compensar a ausência de algum mercado no instante inicial. Adicionalmente, esta reparação depende do fato de os preços de equilíbrio à vista (spot) em $t=1$ serem corretamente antecipados em $t=0$. Adicionando-se negociações contingentes em uma única mercadoria, este procedimento possibilita que se reduza o número de mercados a termo de $L S$ para apenas $S$.

Denota-se agora o vetor de expectativa de preços em todos os estados da natureza por $p^{e} \in \mathbb{R}^{L S}$. Suponha que na data $t=0$ existam transações contingentes em apenas uma única mercadoria física. Seja $q_{1} \in \mathbb{R}^{S}$ o vetor de preços para essas mercadorias contingentes, negociadas em $t=0$ (o sub-índice em questão serve para lembrar que se considera apenas uma única mercadoria física (mercadoria 1) sujeita a transações contingentes). Em face a preços $q_{1}$ e preços spot esperados $p^{e}$, todo consumidor $i$ formula um plano de negociação $z_{i} \in \mathbb{R}^{S}$ para mercadorias contingentes em $t=0$, assim como um conjunto de planos de consumo em mercados à vista $x_{i} \in \mathbb{R}^{L S}$, os quais satisfazem a uma restrição orçamentária.

No modelo de Radner, o consumidor $i$ maximiza a função utilidade $U_{i}\left(x_{i}\right)$, para $\succsim_{i}$, sujeito à restrição orçamentária correspondente a trocas em $t=0, \sum_{s} q_{1 s} z_{s i} \leq 0$, e a restrições orçamentárias para os diferentes mercados à vista, $p_{s}^{e} x_{s i} \leq p_{s}^{e} \omega_{s i}+q_{1 s} z_{s i}$, isto é, o consumo no estado s não excede, em valor, à soma do valor de mercado das dotações iniciais com o valor de mercado dos montantes $z_{s i}$ das mercadorias contingentes compradas ou vendidas à termo em $t=0$. Os planos de consumo $z_{i}^{*}, x_{i}^{*}$ que resolvem esse problema de maximização constituem um equilíbrio de Radner. Nesse modelo, cada consumidor $i$ satisfaz o problema de otimização restrita. Além disso, não se impõe nenhuma restrição ao sinal de $z_{s i}$. Contudo, se $-z_{s i}>\omega_{1 s i}$, ou seja, se para o indivíduo $i$ a disponibilidade do bem 1 (transacionado contingencialmente em $t=0$ ) em $t=1$ e no estado da natureza $s$ for menor do que a obrigação de entrega da mercadoria nessa condição, significa então que em $t=0$ esse indivíduo está vendendo o bem 1 a descoberto. Isto ocorre quando ele vende a $t=0$ o bem 1 contingencialmente a ocorrência do estado $s$ mais do ele terá em $t=1$, caso esse estado ocorra. Evidentemente só será possível manter o compromisso de entrega da mercadoria porque o agente em questão irá comprar no mercado spot, em $t=1$, a quantidade da mercadoria de que não dispõe e que deva entregar neste instante. Há então uma possibilidade de venda a descoberto neste modelo. Tal possibilidade, no entanto, é limitada pelo fato de que o consumo deve ser não negativo para qualquer estado da natureza $s$.

Até aqui apresentamos a implementação sequencial de um equilíbrio de Radner quando há duas datas, e sem consumo em $t=0$. No entanto, as mesmas ideias aplicam-se a uma árvore temporal de eventos na qual vicejam muitos períodos. De fato, num equilíbrio de Radner as trocas ocorrem ao longo do tempo e, em contraste com o cenário de Arrow-Debreu, os agentes econômicos deparam-se com uma sequência de conjuntos orçamentários, um para cada estado em certa data.

Um dos resultados centrais na literatura versando sobre equilíbrio de Radner assegura que este tipo de equilíbrio e o de Arrow-Debreu são idênticos; ou seja, o conjunto de alocações de equilíbrio de Radner, induzidas por negociações contingentes em apenas uma mercadoria, sequencialmente seguidas por trocas à vista, afigura-se igual ao outro conjunto no cenário de Arrow-Debreu induzido pelo arranjo de trocas instantâneas em $L S$ mercadorias contingentes.

As mercadorias contingentes cumprem o propósito de transferir riqueza através de estados da natureza que serão revelados no futuro. No mundo real, existem ativos financeiros que executam, em algum grau, o papel de transferir riqueza; o qual, até aqui, conferimos a essas mercadorias. Uma unidade de ativo financeiro (security) é um título que assegura o direito de receber bens materiais ou dinheiro em $t=1$ num montante que irá depender do estado da natureza que ocorra. Suponha que os payoffs de um título sejam em unidades físicas; assim sendo, o portador do papel receberá um montante $r_{s}$ do bem em questão, na data $t=1$, caso ocorra o estado $s$. O vetor de retornos $r \in \mathbb{R}^{S}$ caracteriza o ativo.

Assume-se que exista um dado conjunto de ativos (uma estrutura de ativos) e que esses ativos possam ser livremente negociados em $t=0$. Cada ativo $k$ é caracterizado por um vetor de retornos 
$\left.r_{(} k\right) \in \mathbb{R}^{S}$. Tem-se $K$ ativos. Suponha ainda que eles sejam negociados em $t=0$. 0 vetor de preços dos ativos negociados no período inicial é simbolizado por $q \in \mathbb{R}^{K}$. O vetor de negociação desses ativos em $t=0$ é denotado por $z \in \mathbb{R}^{K}$. O vetor $z$ representa uma carteira.

Agora se generaliza a definição de equilíbrio de Radner ao introduzir-se ativos financeiros no modelo. Tem-se ainda um preço à vista esperado em um estado $s, p_{s}^{e} \in \mathbb{R}^{L}$. Nesse novo ambiente, o consumidor $i$ maximiza a função utilidade $U_{i}\left(x_{i}\right)$, para $\succsim_{i}$, sujeito à restrição orçamentária correspondente à negociação em $t=0, \sum_{k} q_{k} z_{k i} \leq 0$, e à restrição orçamentária para os diferentes mercados à vista, $p_{s}^{e} x_{s i} \leq p_{s}^{e} \omega_{s i}+\sum_{k} q_{s} z_{k i} r_{s k}$, ou seja, o consumo no estado $s$ não excede, em valor, à soma do valor spot de sua dotação inicial com o valor spot dos retornos de sua carteira. Os planos de carteira $z_{i}^{*} \in \mathbb{R}^{k}$, em $t=0$, e de consumo $x_{i}^{*} \in \mathbb{R}^{L S}$, em $t=1$, que resolvem este problema de maximização constituem um equilíbrio de Radner com ativos. Naturalmente, todo consumidor $i$ satisfaz o problema de otimização condicionada.

Argumentamos anteriormente que, para $S$ mercados contingentes em uma única mercadoria física, obtêm-se resultados equivalentes entre alocações de equilíbrio dos tipos Arrow-Debreu e Radner. Está demonstrado na literatura que essa equivalência mantém-se para modelos com $S$ ou mais ativos, contanto que ao menos $S$ desses retornos sejam linearmente independentes. Em outras palavras, o número efetivo de ativos deve ser no mínimo $S$. Nesse caso, considera-se o mercado de ativos completo. Neste contexto, a introdução de ativos financeiros no modelo de equilíbrio geral canônico preserva as mesmas alocações de equilíbrio. A implicação disso para as propriedades de bem-estar é evidente.

Com uma completa estrutura de ativos, os agentes econômicos estão, com efeito, desimpedidos em transferir riquezas através dos estados. Portanto, no equilíbrio, suas escolhas de carteira induzem os mesmos consumos no segundo período que no equilíbrio de Arrow-Debreu. Infelizmente os mercados podem ser incompletos devido à possibilidade de existirem poucos mercados de ativos. No mundo real, mercadorias contingentes e ativos podem deixar de existir por um número de razões. ${ }^{2}$ Se as possibilidades de transferir-se riqueza através de estados forem limitadas, então pode perfeitamente existir uma perda de bem-estar devida à inabilidade de identificar-se riscos na extensão que seria conveniente. As alocações de equilíbrio de Radner, portanto, não necessitam ser Pareto-ótimas e, em princípio, poderiam existir realocações de consumo que tornariam todos os consumidores ao menos tão bem quanto antes, e ao menos um desses consumidores estritamente melhor. Agora seria possível que as alocações de consumo de algum equilíbrio de Radner passem a depender do estado da natureza e consequentemente que elas falhem no teste de otimalidade de Pareto. ${ }^{3}$

\section{OTIMALIDADE DO EQUILÍBRIO QUANDO O MERCADO É INCOMPLETO}

Considerando-se o papel fundamental do modelo de equilíbrio geral e a aparente ausência de mercados completos, a existência de equilíbrio neste cenário tem sido uma questão teórica de grande interesse. O economista matemático Oliver Hart foi pioneiro na demonstração, sob certas condições, do equilíbrio em mercados incompletos. ${ }^{4}$ No entanto, ele mesmo reconhece que o equilíbrio, em alguns casos, não poderá existir nesse ambiente até mesmo quando observadas certas condições usuais como a hipótese de "preferências suaves". Por meio de um contraexemplo, Hart mostra que um equilíbrio de fato não existirá para certa economia. Tal contraexemplo baseia-se na hipótese de um colapso na possibilidade de o mercado de ativos proteger (to span) todas as contingências que ocorrem em

\footnotetext{
${ }^{2}$ Ver a respeito Mas-Collell et alii (1995, p. 709).

${ }^{3}$ Em geral, se os mercados são completos então o equilíbrio de Radner é Pareto-ótimo; contudo, em alguns casos raros, em que os efeitos das transações são muito enviesados, a soma das utilidades dos agentes em equilíbrio com mercados completos é menor do que a soma das utilidades no equilíbrio com mercados incompletos. Portanto, o equilíbrio de Radner mesmo com mercado completo pode ser subótimo. Veja um paradoxo de otimalidade relacionado em Mas-Collell et alii (1995, p. 712 e Exercício 19. F. 3).

${ }^{4}$ Hart (1975).
} 
um conjunto excepcional de preços à vista inconvenientes. Ele, então, prova matematicamente que, mesmo sob todas as hipóteses padrão de convexidade, um equilíbrio pode deixar de existir. A prova usual da existência de equilíbrio não se aplica a esse cenário porque as correspondências orçamentárias dos consumidores não são semicontínuas superiores (upper semicontinuous). Esta descontinuidade na correspondência orçamentária leva a uma descontinuidade nas correspondências de demanda dos consumidores e, portanto, neste caso, as técnicas usuais não podem ser aplicadas para demonstrar a existência de equilíbrio.

Uma série de estudos segue o legado de Hart. A maioria deles constitui tentativas de ressuscitar a existência do equilíbrio. Assim sendo, tal literatura tem-se concentrado em mostrar que o contraexemplo de Hart é relevante apenas para um conjunto particular de economias, um programa de pesquisa para a demonstração do que foi denominado de existência genérica. A existência genérica resulta de uma série de trabalhos que contam com um número suficiente de ativos para completar o mercado, ao menos para preços à vista convenientes. O programa de pesquisa da existência genérica trata-se de uma aplicação de técnicas de topologia diferencial. Tais técnicas desempenham um papel básico na análise. Na hipótese de que o espaço $\Omega$ nos quais se localizam os possíveis vetores de dotações seja um conjunto aberto, então se pode obter uma família parametrizada de economias. Diz-se que uma propriedade se mantém genericamente se ela é verdadeira em um conjunto aberto de medida completa no espaço de parâmetros $\Omega$.

Podem-se ainda encontrar, na mesma literatura, outros modelos que têm sido exitosos em demonstrar o equilíbrio em mercados incompletos sob a hipótese da existência exclusiva de ativos financeiros com direitos contingentes expressos em unidades de conta que são independentes dos preços à vista. Nesse caso, embora o subespaço de direitos a valores que possa ser alcançado por intercâmbios com ativos não necessite ser completo, ele é então fixado de maneira independente dos preços à vista. Neste cenário, muitos autores têm conseguido demonstrar o equilíbrio em mercados incompletos com ativos puramente financeiros sob condições gerais, sem se basearem na generalidade.

A fim de provar o equilíbrio em mercados incompletos, em uma sequência de dois ensaios, Duffie e Shafer propuseram um modelo básico, na linha da existência genérica. ${ }^{5}$ o primeiro ensaio propõe um modelo de dois períodos, com a informação sobre o estado da natureza sendo revelada no segundo período. Os ativos asseguram direitos à cesta de mercadorias no segundo período, cesta contingente ao estado da natureza; e são insuficientes em número para proteger (to span) todos os direitos contingentes; não obstante os preços de mercado à vista anunciados. No segundo ensaio, os mesmos autores estendem os resultados a economias multiperíodos sob incerteza com trocas sequenciais, e com ativos financeiros mistos: reais e puramente financeiros. Mesmo neste caso, eles provam a existência, exceto para um conjunto excepcional de economias parametrizado por dotações e ativos.

o segundo modelo oferece a vantagem de se trabalhar com economias de multiperíodos; porém, ele impõe restrições de ativos na estrutura da pesquisa, as quais deveriam ser removidas ou ao menos enfraquecidas. Sendo assim, melhores resultados são alcançados no primeiro ensaio, em que pese a simplicidade do contexto de uma economia com apenas dois períodos.

Nesse contexto, dois resultados básicos para mercados incompletos devem ser destacados: um teorema que prova a existência genérica do equilíbrio, ou seja, a sua existência para uma economia com um conjunto de dotações e de ativos que forma um conjunto aberto de medida completa; bem como outro teorema que demonstra a existência de um pseudoequilíbrio com variedade (manifold) $\varepsilon$. Cabe aqui uma breve explicação desses conceitos topológicos. A estrutura de ativos reais $A$ é regular se para cada estado da natureza uma fileira $a_{s}$ puder ser selecionada da matriz A tal que a coleção $\left(a_{s}\right)_{s=1}^{S}$ seja linearmente independente. Se a estrutura de ativos $A$ é regular então o conjunto de preços críticos da data 1 é um conjunto fechado de medida zero em $\mathbb{R}^{L S}{ }^{6}$ Se a estrutura $A$ de ativos reais é regular, então há um conjunto genérico $\Omega^{\prime} \subset \Omega$ tal que existem pontos de equilíbrio cuja dotação

\footnotetext{
${ }^{5}$ Duffie e Shafer (1985a,b).

${ }^{6}$ Magill e Shafer (1991, p. 1541).
} 
correspondente pertence a $\Omega^{\prime}$. O conceito de pseudoequilíbrio refere-se à versão fraca do conceito de equilíbrio com não-arbitragem. No segundo teorema em questão, a técnica chave para se estabelecer a existência genérica de um equilíbrio em mercados incompletos apóia-se na análise global de um pseudoequílibrio.

O modelo de Duffie e Shafer trabalha com $L$ mercadorias físicas. Seja $\omega \in \mathbb{R}_{++}^{I L(S+1)}$ denotando a lista de vetores de dotações. Uma dada estrutura de ativos é representada por $a \in \mathbb{R}^{L S K}$. Os autores parametrizam a economia por um ponto $(\omega, a) \in \mathbb{R}_{++}^{I L(S+1)} \times \mathbb{R}^{L S K}$. Seja $G_{k, s}$ denotando a coleção de subespaços $k$-dimensional de $\mathbb{R}^{S}$. Dado um sistema de preços spot $p \in \mathbb{R}_{++}^{L(S+1)}$ e $\mathcal{L}$ a indicar um subespaço linear de $\mathbb{R}^{S}$, eles definem o pseudoequilíbrio com variedade $\varepsilon$ por $\varepsilon=\{(p, \mathcal{L}, \omega, a) \in$ $\mathbb{R}_{++}^{L(S+1)} \times G_{k, s} \times \mathbb{R}_{++}^{I L(S+1)} \times \mathbb{R}^{L S K}:(p, \mathcal{L})$ é um pseudoequilíbrio para a economia $(\omega, a)$, com $\left.p \omega^{1}=1\right\}$. No qual $\omega^{1}$ é a dotação da primeira mercadoria.

As provas de ambos os teoremas envolvem uma matemática muito avançada de topologia diferencial. Nessa análise, participa de modo fundamental a teoria matemática de grassmannianos, uma classe de variedades de subespaços lineares. O ensaio caracteriza o conjunto de parâmetros relevante formando um equilíbrio como uma variedade.

O uso de topologia diferencial na demonstração do equilíbrio econômico geral não se afigura novidade. Uma variedade topológica trata-se de um espaço topológico que se parece localmente com um espaço $n$-dimencional real. As variedades herdam muitas das propriedades locais de um espaço euclidiano. Em particular, elas são localmente compacta, localmente conectadas, localmente contábeis, localmente contraíveis e localmente "metrizáveis". Consistente com uma topologia natural, o conjunto $G_{k, s}$ fornece a estrutura de uma variedade compacta suave de dimensão $K(S-K)$, chamada de a variedade grassmanniana de um subespaço $k$-dimensional de $\mathbb{R}^{S}$. O grassmanniano consiste em uma variedade canônica que desempenha um papel chave em muitas partes da matemática moderna. 0 modelo em questão, portanto, caracteriza o conjunto relevante de parâmetros que forma um equilíbrio como uma variedade.

Embora as diferentes provas do equilíbrio geral tenham demonstrado a possibilidade de um tipo de alocação de Radner, mesmo com ausência de mercados completos, todas essas provas apresentam limitações básicas: elas arbitrariamente impõem alguma restrição na natureza dos conjuntos que definem o problema. Exemplificando, o conjunto dos preços à vista deve ser de um tipo especial ou o conjunto das carteiras de ativos deve apresentar uma restrição de fronteira inferior. Ou então os modelos estabelecem hipóteses especiais, como a de que os ativos financeiros devam ser independentes dos preços à vista, ou ainda consideram alguma excepcionalidade topológica a respeito do conjunto de dotações. Finalmente, notam-se limitações em modelos que tentam provar o equilíbrio de mercados incompletos de ativos pela construção de um subespaço linear especial em $\mathbb{R}^{S}$ por meio da delimitação do conjunto relevante de parâmetros que formam um equilíbrio.

Outra limitação da maioria dos modelos de equilíbrio geral com mercados incompletos recai no cenário imaginado de apenas dois períodos, com a incerteza removida no segundo período. De fato, o modelo canônico de equilíbrio geral com mercados incompletos considera uma economia de dois períodos, na qual os agentes conhecem o presente, mas enfrentam um futuro incerto. No período 0 (o presente) há apenas um único estado da natureza (estado 0), no qual $I$ agentes comercializam em $L$ mercadorias e $K$ ativos. Então atua o acaso e ele seleciona um dos $S$ estados que ocorreriam no período 1 (o futuro); retomam-se as negociações com mercadorias e os ativos pagam suas promessas.

O modelo de dois períodos não assume que o processo econômico deveria terminar no segundo período. De fato, caso a previsão perfeita não ocorra, alguns acordos não serão realizados e então as negociações voltariam a ocorrer no segundo período com vistas a um terceiro período e assim por diante. Contudo, nesses modelos não se examina o processo de aquisição de informações. A dinâmica temporal assumida nessa classe de modelo consiste apenas em repetir sempre o mesmo processo a cada dois períodos, como a realização de um ciclo recorrente e monótono. 
Em outras palavras, o modelo canônico em questão trabalha com uma árvore de eventos muito simples, sem nenhum exame do processo de aprendizado dos agentes no mercado. Uma alternativa, que infelizmente aparece em poucos estudos na literatura, consiste em formalizar explicitamente o conjunto de informação. Seja $\mathbb{F}_{t}$ a informação disponível no período $t \in T:=\mathbb{N} \cup\{0\}$. $\mathbb{F}_{t}$ é uma partição de $S$. o processo de aprendizagem pode ser matematicamente traduzido pela hipótese de que $t^{\prime}>t$ torna $\mathbb{F}_{t^{\prime}}$ mais fino do que $\mathbb{F}_{t}$. Pode-se propor também uma árvore de eventos mais complexa sumariando a estrutura de incerteza, definida como sendo $D=\left\{(t, \sigma) \in T \times 2^{S}: t \in T, \sigma \in \mathbb{F}_{t}\right\}$, onde um par $\mathfrak{E}:(t, \sigma) \in D$ é chamado de nó e $t(\mathfrak{E}):=t$ é o período de tempo associado. Em $t=0$ não há informação, isto é, $\mathbb{F}_{0}=\{S\}$ e, portanto, há apenas um único nó, denotado por $\mathfrak{E}_{0}$.

Esse tipo de representação matemática permite que se trabalhe com uma árvore de eventos mais realista, a qual lida com o processo de aprendizagem intertemporal em um mundo de incerteza. Infelizmente um tratamento de equilíbrio general com uma complexa árvore de eventos implica em dificuldades técnicas. Mas em que pese o grande esforço matemático exigido, o problema é analiticamente tratável.

\section{INADIMPLÊNCIA NO EQUILÍBRIO GERAL}

Amiúde a inadimplência não desempenha um papel importante nos modelos de equilíbrio geral. Da perspectiva da teoria do equilíbrio geral parece que a inadimplência que é efetivamente observada na economia seria um sinal de desequilíbrio. Entretanto, tal ideia é errônea. Em um mundo de incerteza e mercados incompletos de ativos financeiros, a inadimplência não é incompatível com o equilíbrio. De fato, modelos com inadimplência mais recentes sugerem que ela não interfere no funcionamento ordenado dos mercados.

O fenômeno da inadimplência não é contemplado nos modelos de Arrow-Debreu e Radner. Mas mesmo nestes dois casos os agentes podem prometer entregas de mercadorias que eles pessoalmente não possuam na data da entrega. Pois, ambos aceitam a possibilidade de vendas a descoberto (short sales). No mundo real os agentes podem estar aptos a pagar uma dívida e racionalmente optar pela inadimplência. Ocorre que nos modelos de Arrow-Debreu e Radner assume-se que os agentes não têm como não honrar uma dívida, pois, por hipótese eles são intrinsicamente bons pagadores, que sempre poderão operar no mercado spot a fim de adquirirem as mercadorias de que não dispõem para atender aos compromissos firmados.

Ademais, tendo-se em conta que o equilíbrio de Arrow-Debreu já se constitui num ótimo de Pareto, a inadimplência não poderia promover a eficiência. Todavia, essa conclusão fundamental depende da hipótese subjacente de que os mercados de ativos sejam completos. Em modelos de equilíbrio geral com inadimplência, trabalha-se aqui com a hipótese de mercados incompletos, embora não necessariamente tais mercados devam ser incompletos. ${ }^{7}$

No mercado de ativos, os agentes podem prometer a entrega de bens que eles pessoalmente não possuam; não obstante, eles estarão em condições de atender a essas promessas, pois, outros agentes lhes fazem promessas de entrega. Somente uma formulação de equilíbrio geral habilitar-nos-ia a avaliar as consequências sistêmicas da inadimplência. Em um mundo em que as promessas excedem às dotações físicas, cada inadimplência pode iniciar uma cadeia de reação. Seria interessante então examinar tal cadeia nesse cenário. 0 credor em um ativo cujo pagamento não ocorrera é destituído de meios para a entrega em outro ativo no qual ele é devedor; dessa forma, causará uma inadimplência adicional em algum terceiro ativo, e assim por diante. Os efeitos indiretos da inadimplência podem tornar-se tão importantes quanto os efeitos diretos, mas tais efeitos só poderiam ser bem estudados em modelos de equilíbrio geral.

\footnotetext{
${ }^{7}$ Mesmo em mercados completos pode-se verificar o fenômeno da inadimplência. Para um exemplo, ver o ensaio Mateos-Planas e Seccia (2011). Agradecemos o comentário e a indicação do ensaio por um parecerista anônimo.
} 
De acordo com dois ensaios, Zame (1990) e Dubey et alii (2005), sob hipóteses especiais até mesmo com inadimplência os mercados de ativos chegam a um equilíbrio. Tal equilíbrio certamente não se equipara em bem-estar a um equilíbrio de Arrow-Debreu, mas a presença da inadimplência permite que se alcance um ótimo de Pareto restrito: uma alocação que não pode ser melhorada, no sentido de Pareto, por realocações de consumo entre os estados possíveis. A inadimplência, de fato, tem um papel positivo no mercado de ativos. Mas o efeito salutar da inadimplência depende crucialmente da incompletude do mercado de ativos.

Por que no contexto de incompletude a inadimplência pode ser salutar? $\mathrm{O}$ argumento heurístico subjacente à rigorosa demonstração matemática é que, quando a inadimplência não é possível, a exigência de que as obrigações sejam satisfeitas restringe as carteiras que efetivamente serão negociadas. Quando se admite a inadimplência, porém, algumas obrigações podem não ser satisfeitas; mas isso não é ruim, pois, elas irão ampliar o conjunto de carteiras que seriam efetivamente negociadas.

Destarte, neste ponto devemos explicitar as hipóteses subjacentes às duas teorias em questão. Dubey et alii (2005) constroem um modelo que considera uma taxa de punição $\lambda_{s k}^{i}$ e uma restrição quantitativa $Q_{k}^{i}$ que representa uma fronteira na venda do ativo $k$ pelo agente $i$. Outra hipótese do modelo é a de que os ativos são pensados como formando fundos (pools). Então os compradores dos ativos recebem uma participação pro rata de todas as entregas de diferentes vendedores. Quando os fundos são amplos, um comprador (infinitesimal) pode considerar que ambos os preços, dos ativos e das mercadorias, e a taxa de entrega do fundo não seriam afetados pelo número de participações que ele adquire.

Outras hipóteses do modelo são as de que nenhum agente possua dotação nula, os agentes tenham dotações dependentes dos estados, que inadimplência gere desutilidade e que todas as mercadorias designadas estejam presentes no agregado. Seguindo a tradição de quase todos os modelos de equilíbrio geral (incluindo-se Arrow-Debreu e Radner), a função utilidade $U_{i}\left(x_{i}\right)$ é contínua, côncava e estritamente crescente em $\mathbb{R}^{L S}$

Quando $\lambda_{s k}^{i}$ tende a infinito, o modelo reduz-se ao caso de equilíbrio de mercados incompletos sem inadimplência. Se $Q_{k}^{i}=0$ para todo $i$, os agentes estão essencialmente proibidos de venderem o ativo $k$, e assim tem-se um modelo de Arrow-Debreu sem ativos. A restrição $Q_{k}^{i}$ na venda do ativo $k$ pelo agente $i$ é exatamente a mesma condição necessária para provar-se a existência de equilíbrio geral em mercados incompletos de ativos no caso sem inadimplência. Portanto, o interesse principal do modelo consiste em analisar a situação em que $0<\lambda_{s k}^{i}, Q_{k}^{i}<\infty$. Nesse cenário, seguem-se diversas consequências curiosas. Uma delas é a de que nem todos os ativos do conjunto $K$ são negociáveis. De fato, com inadimplência haverá muitos ativos em $K$ que são precificados pelo mercado, mas que não são vendidos ou comprados. Então, apenas no subconjunto $K^{*} \subset K$ todos os ativos são efetivamente negociados.

As promessas, penalidades e limitação de vendas no subconjunto $K^{*}$ podem ser consideradas como emergindo endogenamente a partir de $K$. Todo ativo em $K \backslash K^{*}$ pode tornar-se "ativo" em função de seus preços e da taxa esperada de entrega. Para $k \in K^{*}$ mercados "ativos", a taxa de entrega é determinada, no modelo, pelas expectativas racionais das entregas efetivas feitas no pool $k$. Para ativos "inativos" $k^{\prime} \in K \backslash K^{*}$, porém, o pessimismo irracional poderia manter as taxas de entrega arbitrariamente baixas, o que por si só tornaria $k^{\prime}$ para sempre inativo. A fim de evitar-se a exclusão permanente de $k^{\prime}$, o modelo em questão supõe que o governo deva intervir para vender quantidades infinitesimais de cada ativo, mantendo, para cada qual, entrega plena em atendimento às suas promessas. $\mathrm{O}$ equilíbrio geral com inadimplência é demonstrado apenas neste cenário. Assim sendo, os autores definem o conceito de equilíbrio com refinamento.

$\mathrm{O}$ artigo em questão prova a existência do equilíbrio com refinamento, no contexto da inadimplência, exatamente sob as mesmas condições necessárias para se provar a existência no contexto de mercados incompletos sem inadimplência. Um equilíbrio com refinamento existe para qualquer $\lambda$ e $Q$ dentro de limites apropriados. 
Zame (1990) também demonstra a existência do equilíbrio geral com inadimplência. De acordo com um teorema provado por ele, com base em certas hipóteses o equilíbrio com inadimplência existe para cada $\lambda$. Uma das principais condições para o equilíbrio neste cenário é que os ativos sejam linearmente independentes. Vejamos alguns detalhes na construção da teoria em tela: Zame constrói um modelo de mercado de ativo no qual a incerteza é descrita por um conjunto contável e infinito dos possíveis estados da natureza. Imagina-se que se expanda um conjunto de ativos disponíveis até a quase completude do mercado. O modelo analisa o que acontece quando se expande o conjunto de ativos disponíveis. 0 autor fixa uma sequência infinita de ativos $k_{j}$, examinando, para cada índice $N$, o mercado de ativo $\mathfrak{S}^{N}$ no qual apenas os ativos $\left\{k_{1}, \ldots, k_{N}\right\}$ estão disponíveis para negociação; e pergunta então sobre o comportamento das alocações de equilíbrio $\mathfrak{S}^{N}$ conforme $N$ tende a infinito.

Conforme $N$ tende a infinito, as alocações de equilíbrio iriam convergir a um equilíbrio de Radner e a uma alocação Pareto-ótima na economia de mercados completos subjacente. Na verdade, isso quase ocorre, mas não exatamente; ocorre apenas quando a condição de que o padrão de consumo futuro seja não-negativo exerça uma restrição no conjunto de carteiras que possam ser negociadas. Se os encargos são tão grandes que eles excedem as dotações, o atendimento deles iria violar a condição de que o consumo seja não-negativo e as carteiras não poderiam ser negociadas. Se tais carteiras são requeridas com o fito de implementar trocas Pareto-ótimas, as alocações viáveis no mercado de ativos poderiam ser ineficientes, e permanecer assim até mesmo caso o conjunto de ativos disponíveis se expanda (ineficiência assintótica).

Ambos os modelos trabalham com a ideia de fundos (pools) de ativos. Consequentemente a punição à inadimplência $\lambda$ é independente de ativos específicos e estados da natureza. Ela é a mesma para todos os consumidores e é proporcional ao montante da inadimplência. Em ambos os casos, toda inadimplência é perfeitamente antecipada (previsão perfeita) e propaga-se igualmente entre todos os credores. Todo agente observa apenas a inadimplência agregada em cada ativo. A cada $\lambda$, um equilíbrio com inadimplência existe.

A eficiência em economias com inadimplência é demonstrada por Zame com base no seguinte efeito: a inadimplência deixa algumas obrigações não satisfeitas e isto ampliará o conjunto de carteiras que realmente possa ser negociado. Tendo-se em vista que a decisão de inadimplir é endógena, essa ampliação parece provável que ocorra precisamente na direção correta que leva à eficiência. Tão logo a sequência de ativos seja completada, o equilíbrio com inadimplência ficará próximo a um Pareto-ótimo. Em complemento a essa tese, Dubey et alii (2005) argumentam que a inadimplência permite grande ampliação nos graus de proteção de contingências oferecidas pelos ativos financeiros. Uma proteção ampliada oferecida por eles irá provavelmente melhorar o bem-estar social; muito embora esse ganho deva ser sopesado em relação às perdas (deadweight loss) com penalidades à inadimplência que dessa forma seriam incorridas.

As penalidades fornecem incentivos para que se cumpram as promessas; além disso, agentes que adquirem má reputação por conta das inadimplências do passado deverão encontrar mais dificuldades em obter novos empréstimos. Incorporar a inadimplência num modelo de equilíbrio geral para mercados de ativos afigura-se uma extensão natural dos modelos anteriores. No entanto, amiúde os modelos não são suficientemente acurados com respeito ao uso da inadimplência. Afinal, o que significa inadimplência? Os modelos em tela assumem que a única consequência dela são as penalidades aplicadas contra os inadimplentes, e que tais penalidades são avaliadas diretamente em termos de utilidade. Tais penalidades são pensadas como proxies para punições econômicas. Não fica claro, entretanto, como poderíamos interpretá-las também como punições extraeconômicas, tais como perda de reputação, obstáculos a ganho de renda no futuro, problemas de consciência etc.

Outra dificuldade é que os modelos não distinguem a inadimplência oriunda de ação estratégica daquela decorrente exclusivamente do azar. Os credores não conseguem observar a causa da inadimplência. Agentes que não possuam recursos para pagar serão punidos tão severamente como seriam se eles tivessem os recursos, mas escolhessem não efetuar o pagamento da dívida. Isto 
enseja comportamentos oportunistas, os quais se fossem incorporados ao modelo poderiam alterar significativamente o seu resultado.

Parece mais natural estudar mercados incompletos associando-os a ativos protegidos com colateral, nos quais a ausência de pagamento acarretaria no confisco da garantia pelo credor. Na prática, o mecanismo de confisco de mercadorias (colaterais) em caso de inadimplência constitui um dispositivo muito importante para a garantia de um pagamento no mínimo parcial. A literatura sobre mercados incompletos tem-se movido nesta direção. Uma extensão do modelo que incorpore o colateral trata-se de uma consequência natural da linha de evolução deste programa de pesquisa.

\section{COLATERAL NO EQUILÍBRIO GERAL}

Uma extensão dos modelos de equilíbrio geral que incorpore ativos financeiros colateralizados não se trata apenas de uma necessidade lógica, mas também de uma questão de fato. Grande parte das operações de empréstimo nas modernas economias é garantida por alguma forma de colateral. A segurança oferecida pelas garantias em ativos financeiros, físicos ou não, na proteção dos empréstimos contra a inadimplência impacta profundamente na eficiência dos mercados.

No novo contexto, os vendedores de ativos financeiros (tomadores de empréstimos) devem adquirir e manter colaterais que irão garantir as promessas de pagamentos feitas por eles. Um efeito evidente é que a dependência do colateral inibe os empréstimos. A entrega prometida pelos ativos financeiros fica limitada pelo valor do colateral em questão. Pelo fato de que o colateral deve ser mantido pelos agentes que mais gostariam de vendê-lo, este tipo de exigência implica em uma perda (deadweight loss) para a sociedade. A dependência de colateral também restringe a expansão dos mercados financeiros, pois, colaterais são escassos. A moderna engenharia financeira oferece produtos, como pirâmides e tranching, que foram desenhados para "esticar" o colateral ao tornar possível que o mesmo colateral seja usado várias vezes ao mesmo tempo.

Aqui, examinam-se oito ensaios que servirão como base de avaliação do estado da arte nessa temática, naturalmente sabendo da existência de numerosos outros ensaios sobre o mesmo tema presentes na fronteira da disciplina. ${ }^{8}$ Todos os ensaios assumem que os indivíduos irão inadimplir sempre que o valor das promessas exceda o valor do colateral, e não o farão caso contrário. Portanto, um devedor pagará sua dívida somente quando ela não exceder o valor do colateral. Por outro lado, o credor espera receber apenas o mínimo entre o direito associado ao empréstimo e o valor do colateral. Fora isso, a inadimplência não oferece nenhum outro empecilho, pois, ela não irá afetar o grau de dificuldade do tomador em contrair novos empréstimos no futuro.

No que tange a modelos de equilíbrio geral com colaterais, inicia-se por avaliar a dinâmica temporal assumida em cada estudo. Curiosamente, nesta seleção de ensaios, quatro estudos consideram uma árvore temporal de eventos muito simples, com apenas dois períodos (Geanakoplos e Zame, 2007, Araújo et alii, 2000, Orrillo, 2006, Steinert e Torres-Martínez, 2007); no entanto, os outros quatro estudos trabalham com uma estrutura temporal mais complexa de horizonte infinito. Assim sendo, Kubler e Schmedders (2001) examinam um modelo de uma economia em que as trocas estendem-se sobre um horizonte de tempo infinito, e que é habitada por agentes heterogêneos de vidas infinitas. Araújo et alii $(2001,2008)$ consideram uma economia em tempo discreto com horizonte infinito. Eles assumem períodos contáveis e um número finito de ramos em cada nó. Ferreira e Torres-Martínez (2010) também trabalham no contexto de horizonte infinito, porém, analisam apenas o problema da decisão de um único agente.

Pretendemos ainda sublinhar outro aspecto, agora no que diz respeito à natureza do colateral, qual seja: se ele é exógeno ou endógeno no contexto do modelo. As pesquisas de Orrillo (2006) e Steinert e Torres-Martínez (2007) concernem a colaterais exógenos como um meio de obrigar ao cumprimento

\footnotetext{
${ }^{8}$ Araújo et alii (2000), Araújo et alii (2001), Kubler e Schmedders (2001), Orrillo (2006), Geanakoplos e Zame (2007), Steinert e Torres-Martínez (2007), Araújo et alii (2008), Ferreira e Torres-Martínez (2010).
} 
de promessas. Neste último estudo, os autores imaginam que os tomadores podem negociar ativos financeiros reais, os quais estão sujeitos à inadimplência e são suportados por requisições de colaterais físicos. Tais ativos são denominados de primitivos. Vicejam também derivativos: a securitização por ativos de contratos de dívidas que se tornam fundos comuns (pools) pela ação de intermediários financeiros. Formalmente, um número finito de ativos primitivos $k \in K$ garantidos por colaterais pode ser vendido em $t=0$ por preços unitários $q_{k} \in \mathbb{R}_{+}^{K}$. Quando um agente $i$ vende $\varphi_{k}^{i}$ unidades de primitivos $k$, ele paga um montante $q_{k} \varphi_{k}^{i}$ e é obrigado a constituir uma cesta $C_{k} \varphi_{k}^{i}$. $C_{k}$ constitui a exigência unitária de colateral de $k$, a qual todos os agentes tomam como dada. Portanto, nesse ensaio o colateral é exógeno. A hipótese de que as exigências de colateral físico sempre serão atendidas assegura que, no equilíbrio, as vendas a descoberto (short sales) de primitivos serão limitadas.

Em Araújo et alii (2008), o colateral é exógeno, porém, só é constituído quando os ativos são vendidos a descoberto. Na verdade, a maioria dos modelos trabalha com determinação endógena tanto de colaterais quanto da estrutura de ativos. Neste caso, os ativos que estão disponíveis para o intercâmbio não necessariamente serão negociados no equilíbrio, e o conjunto dos que forem realmente negociados será determinado endogenamente pelos mercados. Ao introduzir-se um cardápio de ativos financeiros, no equilíbrio apenas alguns deles serão negociados, e dessa forma também se determina uma margem endógena de requisição.

Nota-se que a despeito do fato de que a margem exigida de colateral possa ser fixada em $t=0$, em outros nós $\mathfrak{E} \in D$ a garantia colateral pode ir depreciando ao longo da árvore de eventos. Então o valor efetivo do colateral depende dos preços, que são endogenamente determinados pelo modelo. Ademais, em caso de depreciação os tomadores podem precisar adquirir recursos físicos adicionais com o fito de manterem suas posições de dívida (short-positions) originais. Tal mecanismo, em certo sentido, assemelha-se à bem conhecida prática de mercado de chamamento de margem. Essa questão é considerada em Araújo et alii (2008). Também em Ferreira e Torres-Martínez (2010) existe um mecanismo de sanção adicional ao lado do confisco de colaterais. Nesse ensaio, os autores analisam de que forma a interação entre garantias colaterais e mecanismos genéricos de sanção adicionais estende o resultado para além do que era conhecido de estudos anteriores. Supõe que em caso de inadimplência os agentes possam ser penalizados não apenas pelo confisco de uma cesta depreciada de colaterais, mas também por punições que são incorporadas em suas preferências. Com essas penalidades, o mercado poderia induzir os agentes a pagar mais do que o valor do colateral em $t=1$.

Um terceiro aspecto que se poderia analisar leva em conta o fato de o colateral servir a apenas um único ativo ou a muitos deles. O modelo básico descreve um cenário no qual todos os ativos estão colateralizados por bens duráveis e cada bem durável pode colateralizar somente um ativo. Em adição, um modelo mais elaborado permite a presença de um fundo (pool) de ativos. Tais fundos podem ser colateralizados por bens duráveis ou por outros ativos, os quais, por seu turno, são colateralizados por bens duráveis (esquema de pirâmide) e permitem que os mesmos bens e ativos colateralizem muitos ativos ao mesmo tempo (tranching).

Geanakoplos e Zame (2007) trabalham com fundos de ativos, e demonstram que tal cenário também é consistente com equilíbrio. Esse modelo admite ativos reais e nominais, e também opções e outros derivativos mais complicados. Kubler e Schmedders (2001) não estão interessados em fundos, até porque eles trabalham com um único bem de consumo perecível. Na verdade, o propósito desse estudo é o de aproximar o equilíbrio numericamente no cenário no qual se considera que todas as variáveis exógenas são estacionárias. Araújo et alii (2000) permitem alguma forma de tranching. Fundos de hipotecas são repartidos em diferentes tranches e vendidos a investidores individuais na forma de derivativos. Todos os credores enfrentam os mesmos riscos quando compram um ativo financeiro, o qual deve ser percebido como um ativo composto, como um derivativo dos ativos personalizados. Nesse sentido, os credores evitam o problema de execução da dívida quando se compram ativos somente de tomadores com elevada propensão à inadimplência.

Em Steinert e Torres-Martínez (2007) as dívidas são reunidas em fundos (pooled) na forma de obrigações de empréstimo colateralizadas, as quais permitem diferentes níveis de prioridades (seniority) 
em caso de inadimplência entre tranches de um mesmo fundo. Os direitos são agrupados (pooled) em derivativos. Esses pools de contratos são famílias de tranches, que recebem pagamentos de acordo com uma estrutura de subordinação hierárquica a qual garante que tranches com prioridade mais baixa não receberão nada antes que as de alta prioridade sejam completamente pagas. Já que os mercados financeiros são anônimos, os credores tomam as taxas de pagamento dos derivativos como dadas.

Steinert e Torres-Martínez estendem as provas do equilíbrio com colateral de forma a abarcar o caso no qual os intermediários podem subscrever mais de um derivativo; permitindo assim uma estrutura de subordinação hierárquica. Com esse propósito, os autores tomam emprestado o conceito, já visto, de equilíbrio com refinamento de Dubey et alii (2005), de modo a evitar a "patologia" na qual os credores apresentam uma crença muito pessimista sobre as taxas futuras de pagamento. Enquanto que no contexto original de equilíbrio com refinamento utiliza-se um agente externo (o governo) que compra e vende unidades de cada ativo com o fito de assegurar uma taxa de entrega infinitesimal mínima, no modelo com colateral a própria garantia associada evita crenças superpessimistas, pois, os credores esperam receber um pagamento positivo quando a cesta de colaterais depreciados dos ativos primitivos subjacentes possuírem um valor diferente de zero. Então eles provam a existência de um equilíbrio com refinamento no cenário com colateral.

Na literatura, diversos estudos procuram demonstrar teoremas que caracterizem a existência do equilíbrio em um ambiente mais geral com árvore temporal de eventos complexa, sumarizando deste modo a estrutura de incerteza. O propósito desses estudos é o de provar a existência do equilíbrio geral para uma árvore de eventos com um número indefinido de etapas. Mas nota-se que quatro dos ensaios aqui considerados consideram apenas uma economia de dois períodos. ${ }^{9}$ Além da diferença na complexidade da árvore de eventos, os modelos possuem hipóteses específicas. Por exemplo, a depreciação de ativos ao longo do tempo varia de um modelo a outro. As mercadorias podem ser estocadas por muitos períodos em uma estrutura específica ou podem depreciar-se em apenas um único período. A Tabela 1 mostra a classificação dos oito artigos aqui discutidos com base nos três critérios comentados anteriormente:

(1) quanto à estrutura da árvore de eventos,

(2) se as requisições de colaterais são feitas exogenamente ou se é assumido um nível endógeno de requisições e

(3) quando se trata de um modelo que supõe um processo de colateralização simples ou uma estrutura mais sofisticada na qual as dívidas estão agrupadas em fundos (pools).

A distinção (2) é importante. Com colaterais exógenos é necessário examinar se existe um equilíbrio geral para cada combinação deles. Enquanto que nos modelos de equilíbrio com níveis de colateral endógenos os estados de equilíbrio obtidos por cada nível implicam, se tal equilíbrio existe, uma adequada requisição endógena de colateral.

Nota-se que o estudo mais geral é o de Kubler e Schmedders (2001), exceto que eles não lidam com uma estrutura mais sofisticada de agrupamento (pool) de ativos. Por outro lado, os modelos de Geanakoplos e Zame (2007) e Araújo et alii (2000) apresentam a conveniência de trabalharem com colaterais endógenos e um pool de ativos, mas sua árvore de eventos é muito simples. É impossível dizer, sem muita qualificação, qual modelo é superior a outro. Na verdade, a avaliação depende dos objetivos da investigação. Enfocar o ambiente mais simples pode ser mais produtivo para certos propósitos. Por exemplo, Ferreira e Torres-Martínez (2010) consideram que eles necessitam apenas de um agente para alcançar conclusões sobre a precificação de ativos em mercados de crédito competitivos. De fato, com a abordagem da forma reduzida para as adicionalidades contra a inadimplência, o mecanismo de precificação torna-se mais tratável.

\footnotetext{
${ }^{9}$ Geanakoplos e Zame (2007), Araújo et alii (2000), Orrillo (2006) e Steinert e Torres-Martínez (2007).
} 
Tabela 1: Classes de modelos de equilíbrio geral com colateral para oito ensaio examinados

\begin{tabular}{l}
\hline MODELOS DE DOIS PERÍODOS \\
\hline Colateral exógeno e uma colateralização simples da dívida \\
Orrillo (2006) \\
Colateral exógeno e um pool de ativos \\
Steinert e Torres-Martínez (2007) \\
Colateral endógeno e uma colateralização simples da dívida \\
Nenhum \\
Colateral endógeno e um pool de ativos \\
Geanakoplos e Zame (2007), Araújo et alii (2000) \\
\hline MODELOS DE HORIZONTE INFINITO \\
\hline Colateral exógeno e uma colateralização simples da dívida \\
Araújo et alii (2001, 2008) \\
Colateral exógeno e um pool de ativos \\
Ferreira e Torres-Martínez (2010) \\
Colateral endógeno e uma colateralização simples da dívida \\
Kubler e Schmedders (2001) \\
Colateral endógeno e um pool de ativos \\
Nenhum
\end{tabular}

Levando-se em conta essas considerações metodológicas, vejamos os principais teoremas demonstrados na literatura. A Tabela 2 apresenta os teoremas provados em cada artigo que atraíram nossa atenção. Não comentamos outros teoremas, contidos nesta seleção, que são muito técnicos e específicos em detalhes. Assinala-se o ambiente em que os teoremas são demonstrados (compare com a Tabela 1). A existência do equilíbrio segue da escassez de colaterais físicos exigidos, o que assegura que as vendas de ativos a descoberto (short sales) são limitadas no equilíbrio. Há apenas uma exceção que é a pesquisa de Ferreira e Torres-Martínez (2010). Esse modelo mostra que existe uma fronteira superior estritamente positiva tal que se a cesta de colaterais satisfaz essa fronteira então o problema do agente $i$ não possui uma solução fisicamente viável.

Todos os artigos em questão são muito técnicos e cada qual requer um considerável esforço de trabalho matemático para uma ampla compreensão que abarque todas as passagens. É claro, que esses ensaios requereram um esforço ainda maior por parte de seus criadores. 
Tabela 2: Os principais teoremas, na literatura selecionada, com respeito a equilíbrio com colaterais

Geanakoplos e Zame (2007): dois períodos, colateral endógeno e pool de ativos

TEOREMA 1: Sob hipóteses a respeito de comportamento e previsão dos agentes que são padrão na literatura do equilíbrio geral, um equilíbrio com colateral sempre existe.

TEOREMA 2 : Limites ao endividamento constituem uma implicação necessária dos esquemas de empréstimos colateralizados.

TEOREMA 4: Em um modelo de dois períodos, assume-se que não exista incerteza sobre os estados da natureza na data 1. Se cada consumidor é um poupador líquido (gastos em cada estado na segunda data devem ser, no máximo, tão grandes quanto o valor da dotação somado ao retorno dos ativos), o equilíbrio walrasiano é equiparado a um equilíbrio com colateral (com os mesmos preços na data 2 ).

TEOREMA 5: Se as funções de utilidade do consumidor $U^{1}, \ldots, U^{I}$ são suaves e satisfazem a condição de fronteira, então existe um conjunto aberto de perfis de dotação com a propriedade que nenhum equilíbrio com colateral surgido de um perfil pode ser Pareto-ótimo (mesmo que todos os ativos estejam disponíveis para troca). TEOREMA 6: Todo conjunto de planos de equilíbrio com colateral é Pareto-ótimo entre todos os conjuntos de planos que: (a) sejam socialmente viáveis; (b) que considerem qualquer decisão assinalada na data 0 , e que digam respeito a cada conjunto de orçamento do consumidor, associado a cada estado $s$ na data 1 , a preços de equilíbrio dados; (c) que chamem para a entrega ativos que representam o mínimo entre a promessa e o valor do colateral.

TEOREMA 7: Toda economia com ativos colateralizados e pools de ativos, satisfazendo a alguma hipóteses (dotações positivas, $U^{i}$ é contínua e quase-côncava etc.) admite um equilíbrio.

Steinert e Torres-Martínez (2007): dois períodos, colateral exógeno e pool de ativos

TEOREMA 1: Sob algumas hipóteses ( $U^{i}$ é contínua, côncava e estritamente crescente, para cada ativo as exigências de colateral são diferentes de zero, etc.) uma economia com o conjunto $S$ de estados da natureza, certo conjunto de características dos agentes, certa estrutura física de mercado e algumas estruturas financeiras tem um equilíbrio não-trivial (ele é não-trivial se as taxas de pagamento esperadas não são super-pessimistas).

Kubler e Schmedders (2001): horizonte infinito, colateral endógeno e pool de ativos

TEOREMA 1: Sob certas condições matemáticas, existe uma correspondência de equilíbrio que corresponda a um equilíbrio no mercado financeiro.

Orrillo (2006): dois períodos, colateral exógeno e colateralização simples da dívida

TEOREMA 2: Sob certas hipóteses ( $U^{i}$ é contínua, côncava e estritamente crescente, para cada ativo as exigências de colateral são diferentes de zero, dotações positivas etc.) a economia possui um equilíbrio de colateral exógeno.

Ferreira e Torres-Martínez (2010): horizonte infinito, colateral exógeno e pool de ativos

TEOREMA 1: Sob certas condições (os recursos físicos agregados ocupados no nó $\mathfrak{E}$ são positivos na árvore de eventos $D, U^{i}$ é contínua, côncava, estritamente crescente e finita), suponha que os mecanismos de coerção adicionais são persistentemente efetivos em uma sub-árvore $D(\mathfrak{E})$. Independentemente dos preços $(p, q)$ há fronteiras superiores estritamen-te positivas $\left(\Psi_{\eta}\right)_{\eta \in D(\mathfrak{E})}$ tais que, se as cestas de colaterais satisfazem $\min \sum_{l \in L} C_{(\eta, j, l)}<\Psi_{\eta}$ então o problema do agente $i$ não tem uma solução fisicamente viável.

Araújo et alii (2000): dois períodos, colateral endógeno e pool de ativos

TEOREMA 1: Suponha que $U^{i}$ seja contínua, côncava e estritamente crescente, e $\omega \in L$ então a economia tem um equilíbrio.

Araújo et alii (2001): horizonte infinito, colateral exógeno e colateral-zação simples da dívida

TEOREMA 1: Se para cada nó $C_{\mathfrak{E}, j} \neq 0$ e se $U^{i}$ é separável em tempo e em estados do mundo, e é estritamente crescente e limitada, então existe um equilíbrio.

Araújo et alii (2008): horizonte infinito, colateral exógeno e colateral-zação simples da dívida

TEOREMA 1: Para uma economia na qual para todos os agentes $\omega \in \mathbb{R}_{++}^{D \times L}, U^{i}$ é contínua, estritamente quase-côncava, e $U^{i}(0)=0$, e colateral $C_{\mathfrak{E}, j} \neq 0$ para todo $(\mathfrak{E}, j)$ em $D$, então existe um equilíbrio. 


\section{CONCLUSÃO}

Qual é a principal mensagem que podemos aprender dessas pesquisas muito avançadas na teoria do equilíbrio geral com inadimplência e colateral? Essa linha de investigação tem menos de vinte anos, um tempo muito curto para a ciência econômica. Na verdade, há muitos problemas nos modelos sugeridos. Exemplificando, no modelo com inadimplência e colateral o tratamento da inadimplência não é realista. Em muitas situações econômicas, a inadimplência leva à perda da reputação do tomador, o que tem efeito em sua capacidade de voltar a tomar emprestado no futuro. Em geral, quando se declara a falência pessoal, tal fato resulta numa perda de todos os ativos e é muito difícil inadimplir apenas em alguns empréstimos enquanto se mantém o colateral preso a outros. Steinert e Torres-Martínez (2007) supõem que em caso de inadimplência os agentes devam ser penalizados não apenas com o confisco de uma cesta de colaterais depreciados, mas também com penalidades que são incorporadas em suas preferências. Com essas penalidades, o mercado pode induzir os agentes a pagar mais do que o valor do colateral em $t=1$.

Enfim, qual a principal conclusão dessa literatura? Muitos teoremas sugerem que uma economia com ativos colateralizados satisfazendo algumas hipóteses admitem o equilíbrio. Os artigos utilizam, no entanto, diferentes conceitos de equilíbrio. A Tabela 2 cita dois deles: correspondência de equilíbrio e equilíbrio não-trivial (é não-trivial se a taxas de pagamento esperada não são superpessimistas). Os teoremas também fazem assertivas sobre as propriedades de bem-estar do equilíbrio demonstrado por eles: todo conjunto de equilíbrio com colateral é um Pareto-ótimo restrito, um ótimo entre todos os conjuntos de planos que atendem uma condição geral.

\section{BIBLIOGRAFIA}

Araújo, A., Orrillo, J., \& Páscoa, M. R. (2000). Equilibrium with default and endogenous collateral. Mathematical Finance, 10:1-21.

Araújo, A., Páscoa, M. R., \& Torres-Martínez, J. P. (2001). Collateral avoids Ponzi schemes in incomplete markets. Ensaios econômicos, Fundação Getulio Vargas, Rio de Janeiro.

Araújo, A., Páscoa, M. R., \& Torres-Martínez, J. P. (2008). Long-lived collateralized assets and bubbles. Serie Documentos de Trabajo 284, Universidad de Chile, Santiago.

Dubey, D., Geanakoplos, J., \& Shubik, M. (2005). Default and punishment in general equilibrium. Econometrica, 73:1-37.

Duffie, D. \& Shafer, W. (1985a). Equilibrium in incomplete market: I. Journal of Mathematical Economics, 14:285-300.

Duffie, D. \& Shafer, W. (1985b). Equilibrium in incomplete markets: II. Generic existence in stochastic economies. Working paper, Mathematical Sciences Research Institute.

Ferreira, T. R. T. \& Torres-Martínez, J. P. (2010). The impossibility of effective enforcement mechanisms in collateralized credit markets. Journal of Mathematical Economics, 46:332-342.

Geanakoplos, J. \& Zame, W. R. (2007). Collateralized asset markets. Working paper, University of California, Los Angeles.

Hart, O. (1975). On the optimality of equilibrium when the market structure is incomplete. Journal of Economic Theory, 11:419-443.

Kubler, F. \& Schmedders, K. (2001). Stationary equilibria in asset-pricing models with incomplete markets and collateral. In University, S., editor, General Equilibrium Conference, Stanford. 
Magill, M. \& Shafer, W. (1991). Incomplete markets. In Hildenbrand, W. \& Sonnenschein, H., editors, Handbook of Mathematical Economics, volume IV, chapter 30. North Holland.

Mas-Collell, A., Whinston, M. D., \& Green, J. R. (1995). Microeconomic Theory. Oxford University Press, New York-Oxford.

Mateos-Planas, X. \& Seccia, G. (2011). Consumer default with complete markets : Risk-based pricing and finite punishment. Discussion Papers in Economics and Econometrics 1105, School of Social Sciences, Economics Division. Southampton : Univ. of Southampton.

Orrillo, J. (2006). Another proof of the existence of GEI equilibrium with default and exogenous collateral. Brazilian Review of Econometrics, 26:155-170.

Radner, R. (1972). Existence of equilibrium of plans, prices and price expectations in a sequence of markets. Econometrica, 40:289-303.

Radner, R. (1982). Equilibrium under uncertainty. In Arrow, K. \& Intriligator, M. D., editors, Handbook of Mathematical Economics, volume II, chapter 20. North-Holland, Amsterdam.

Steinert, M. \& Torres-Martínez, J. P. (2007). General equilibrium in CLO markets. Journal of Mathematical Economics, 43:709-734.

Zame, W. R. (1990). Efficiency and the role of default when security markets are incomplete. Working Paper 585, UCLA. 